\title{
Effects of type and mode of propulsion on hand-cycling biomechanics in nondisabled subjects
}

\author{
Arnaud Faupin, PhD; ${ }^{1 *}$ Philippe Gorce, PhD; ${ }^{1}$ Christophe Meyer, $\mathrm{MS}^{2}$ \\ ${ }^{1}$ Laboratory of HANDIBIO, Université du Sud Toulon-Var, La Garde, France; ${ }^{2}$ Department of Rehabilitation Sciences, \\ Katholieke Universiteit Leuven, Faculty of Physical Education and Physiotherapy, Leuven, Belgium
}

\begin{abstract}
This study investigated the range of motion (ROM) (in degrees) of the upper limb and trunk, forces (Newtons), twodimensional fraction effective force $\left(\mathrm{FEF}_{2 \mathrm{D}}\right)$ (in percent), and torque (Newton meters) during hand cycling. Seven nondisabled participants performed a 1 min exercise test at $70 \mathrm{rpm}$ on a hand cycle (HC) fixed to an ergometer in synchronous (SC) mode versus asynchronous (AC) mode and in arm-power (AP) versus arm-trunk-power (ATP) type of propulsion. Higher $(p<0.001)$ flexion/extension of the trunk was found during ATP versus AP type and higher $(p<0.001)$ lateral flexion and rotation of the trunk in AC versus SC mode. The trunk ROM should explain the different force generation patterns observed in this investigation between AC and SC modes and AP and ATP types. However, kinetic results do not allow the most effective type or mode of propulsion $\left(\mathrm{FEF}_{2 \mathrm{D}}\right.$ : from $72.9 \%$ to $\left.89.3 \%\right)$ to be established. We conclude that trunk movement is an important parameter to consider in ergonomically optimizing hand cycling. Nevertheless, future studies in experienced HC users, especially with limited trunk function, should be performed.
\end{abstract}

Key words: asynchronous, backrest, hand bike, hand cycle, kinematics, kinetics, rehabilitation, synchronous, trunk, wheelchair.

\section{INTRODUCTION}

Arm-crank propulsion, also called hand-bike or handcycle (HC) propulsion, has been developed over the last 20 years and is now widely used in rehabilitation programs for persons with reduced mobility and in the sports field for the disabled. Indeed, in 2004, it became a Paralympic discipline for the first time. Investigations comparing physiological responses during arm-crank ergometry [1-4] or hand cycling [5-6] have shown that arm cranking is less strenuous and more efficient - in terms of mechanical efficiency and cardiorespiratory responses - than hand-rim wheelchair propulsion. Because of the current booming development in arm cranking, a variety of HCs exist with different backrest and seat adjustments and crank-axle heights and crank configurations, such as synchronous (SC), where cranks are in parallel position, and asynchronous (AC), where cranks are in alternate position $180^{\circ}$ to each other.

Research regarding arm cranking and hand cycling is often limited to studies evaluating the physiological responses [5-11]. Different reviews by Van der Woude et al. report that few studies on the biomechanics of hand cycling exist [12-13]. Physiological literature on SC or AC mode shows contradictory results. Generally, studies on physiological responses between AC and SC arm-crank

\footnotetext{
Abbreviations: 2-D = two-dimensional, 3- $\mathrm{D}=$ three-dimensional, $\mathrm{AC}=$ asynchronous, $\mathrm{AP}=$ arm-power, $\mathrm{ATP}=$ arm-trunk-power, B45 = backrest angle of $45^{\circ}$, B85 = backrest angle of $85^{\circ}, \mathrm{C} 7=$ seventh cervical vertebra, $\mathrm{F} / \mathrm{E}=$ flexion/extension, $\mathrm{FEF}=$ fraction effective force, $\mathrm{HC}$ = hand cycle, $\mathrm{K}=$ kneeling position, $\mathrm{L} 3=$ third lumbar vertebra, $\mathrm{ROM}=$ range of motion, $\mathrm{SC}=$ synchronous, $\mathrm{SD}=$ standard deviation, $\mathrm{WB}=$ without backrest.

*Address all correspondence to Arnaud Faupin, PhD; Université du Sud Toulon-Var; Laboratoire HandiBio EA 4322, avenue de l'université, BP20132, 83957 La Garde Cedex, France; +33-04-94-14-27-57; fax: +33-04-94-14-29-48.

Email: faupin.arnaud@aliceadsl.fr

DOI:10.1682/JRRD.2010.10.0199
} 
ergometry reveal no difference between the two crank modes [14-16]. Moreover, a recent study by GooseyTolfrey and Sindall finds significantly higher efficiencies during submaximal AC versus SC mode of propulsion in subjects who were wheelchair-dependant trained [17]. In contrast to previous results in arm-crank ergometry, different investigations show that SC hand cycling is less strenuous and more efficient than AC hand cycling [18-23]. Among these studies, different authors emit the hypothesis that the beneficial effects of the SC mode may also be caused by the larger effective muscle mass of the trunk [20-21], which would allow the weight of the trunk to be effectively used in propulsion.

Moreover, based on body position on the HC, two types of propulsion exist [24-25]: arm-power (AP) and armtrunk-power (ATP). The sitting position (upright, semirecumbent, kneeled, and bent forward) determines whether the HC is powered with the arms only or with the arms and trunk [26]. However, only persons with functional trunk muscles and good abdominal strength can use ATP propulsion [25]. We are aware of only one study by Faupin et al. that focuses on a kinematics comparison between AP and ATP propulsions [24]. This recent study investigated the effects of backrest position and gear ratio on hand-cycling sprinting performance in 10 nondisabled participants. The results showed that participants had statistically higher trunk flexion/extension (F/E) and maximal velocity without use of a backrest [24]. The authors suggested that HC users' performance improves when they use ATP propulsion.

From that context, obviously, trunk action is an important factor for mode of propulsion (SC vs AC) and type of propulsion (AP vs ATP). Thus, the main goals of this study are to-

1. Evaluate the effects of HC configuration and mode of propulsion in trunk movement in a group of nondisabled participants.

2. Investigate a possible difference in kinetics and kinematics of the upper limb between SC versus AC mode and AP versus ATP type of propulsion.

\section{METHODS}

\section{Experimental Protocol}

Once on the HC attached to the ergometer (Figure 1), we gave the participants 10 minutes to get accustomed to the equipment. Each participant performed a submaximal 1 min exercise test at a 70 rpm-cycle frequency, imposed by

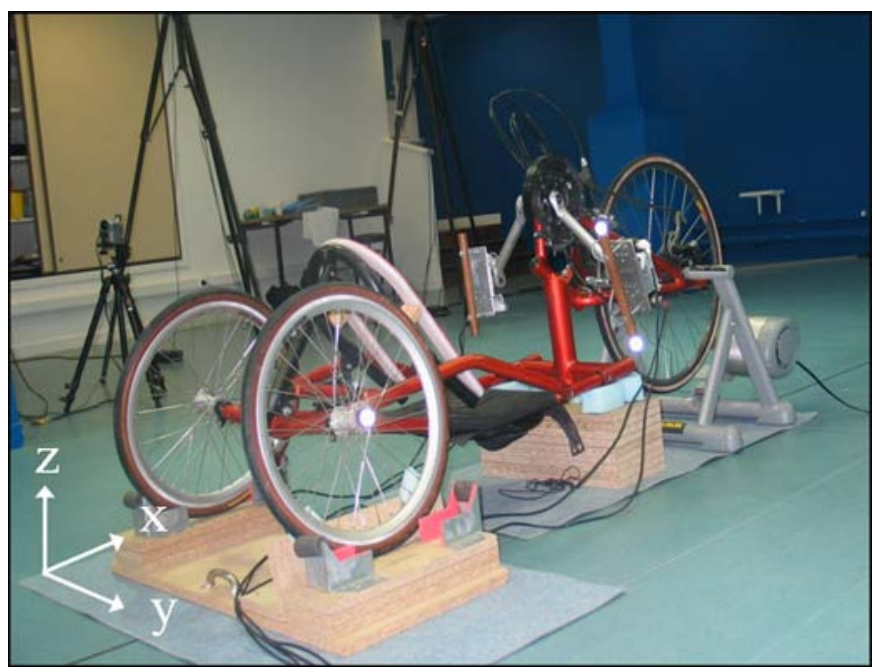

Figure 1.

Hand cycle fixed to ergometer with dynamometric pedal. Backrest was modified to make marker on trunk visible. $x$-, $y$-, and $z$-axes $=$ three-dimensional coordinates in global reference system.

a metronome (sound signal). They repeated the test according to SC (parallel cranks) and AC (cranks in alternate position, $180^{\circ}$ to each other) crank modes and two types of propulsion, AP and ATP, for four body positions on the HC with different backrest and seating adjustments (backrest angle of $45^{\circ}$ [B45], backrest angle of $85^{\circ}$ [B85], without backrest [WB], and kneeling position [K]) (Figure 2) [27]. The different tests were randomly performed among participants to avoid learning and/or fatigue effects during the experiment. A complete recuperation period of at least 5 min was imposed between each test, during which the experimenter adjusted the HC. Moreover, the participant had 5 min to become accustomed to the new adjustments (mode or type of propulsion). Type of propulsion technique was not recommended to the participants before each test.

We collected kinematic and kinetic data on the right side during the last $30 \mathrm{~s}$ of the $1 \mathrm{~min}$ exercise test. In addition, we analyzed the first five complete crank cycles of the $30 \mathrm{~s}$ measurements for all parameters.

\section{Hand Cycle and Ergometer}

We use an adjustable sports HC (Sopur, Spirit 470; Heidelberg, Germany) for the study (Figure 1). The handgrips were in a neutral position, and the length of the standard cranks was $180 \mathrm{~mm}$. For all tests, tire pressure was set at 8 bars. The HC was affixed to an electromagnetically braked ergometer (Elite Axiom; Fontaniva, Italy). The Elite Axiom ergocycle is equipped with a motor unit, which 


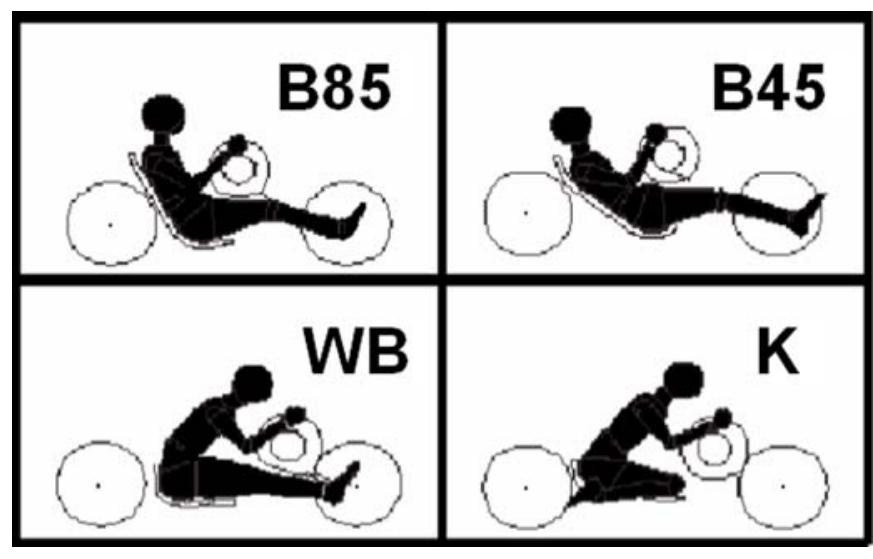

Figure 2.

Schematic of four different hand-cycle testing positions. (Reproduced by permission from Van Breukelen K. Handbikes: Arm power versus arm trunk power, an ergonomic classification of handbikes [Internet]. Gouda: the Netherlands; Arm Powered by Double Performance; 2001 [cited 2010]. Available from: http://www.handbike.de/archiv/2002/ downloads/arm-vs-trunk.pdf) B45 = backrest angle of $45^{\circ}$, B85 = backrest angle of $85^{\circ}$, $\mathrm{WB}=$ without backrest, $\mathrm{K}=$ kneeling position.

imposes a constant rolling resistance on the front wheel [28-29]. A virtual slope represents the rolling resistance and is chosen by the investigator using the software of the Elite Axiom (1\% in the present study).

For the three seating positions, the participants' feet were placed on the footrests. According to Mossberg et al.'s study, placement of the feet on the footrest reduces participants' ability to use their lower limbs for stabilization [16]. The HC used for the study was an AP bike (Sopur, Spirit 470), so the seating was adapted for kneeling (Figure 3). To correct for differences in subject height, we adjusted the seating position by changing seat or back cushions. We adjusted the seating position in relation to the backrest to obtain the same extension of the elbow $\left(15^{\circ}-\right.$ $20^{\circ}$ ) for each participant and to not allow complete elbow extension during maximal reach [16].

\section{Kinematic Data}

A portion of the kinematic data is similar to Faupin et al.'s protocol [24]. For this portion, we set in quotes.

"A three-dimensional [3-D] movement analysis was performed with a Vicon 370 system (Oxford Metrics; Oxford, United Kingdom), with a sample rate of $60 \mathrm{~Hz}$. This measurement system comprises six digital cameras equipped with an infrared flash system. Marker locations are similar to Faupin et al.'s protocol [24,29-30]. We placed 22 anatomical and technical markers on the participants

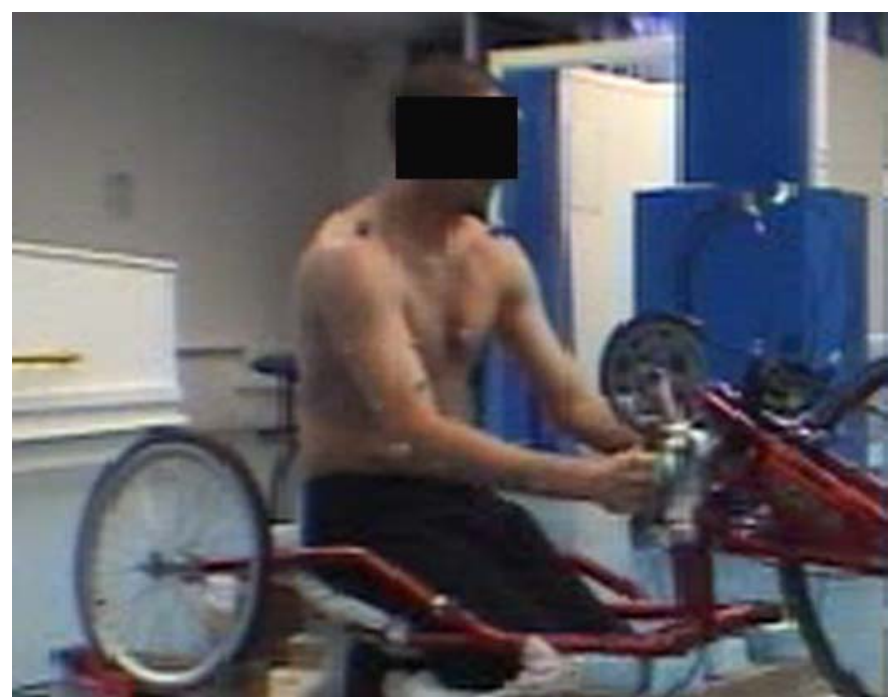

Figure 3.

Hand cycle adapted for kneeling position.

(anatomical markers: one on the forehead, the chin, the sternum, the seventh cervical vertebra [C7], and the third lumbar vertebra [L3]; two on the acromions, the temples, the styloid process of the radius and cubitus, and the metacarpals of the auricular and index. Technical markers: four markers are attached to the upper arm and three to the forearm). The reflective markers were spherical: $25 \mathrm{~mm}$ for the anatomical markers and $9 \mathrm{~mm}$ for the technical markers. The technical markers allowed us to use Roux et al.'s global optimization method, significantly minimizing measurement errors due to sliding of the skin" [31]. We modified the backrest in such a way as to make the marker on L3 visible (Figure 3).

We calibrated the capture volume before the start of each test. Based on the static trial, anatomical frames were defined according to the recommendations of the International Society of Biomechanics [32]. Before the actual measurement, we used a static trial to determine the joint rotation centers. In the absence of movement and thus of skin movement, we measured the anatomic marker positions. "According to the method of Schmidt et al. [33], the shoulder center is assumed to be $7 \mathrm{~cm}$ inferior to the acromion marker, which is the average of visually determined distances using a ruler. The elbow joint center is the middle between the medial and lateral elbow markers. The joint center of the wrist is the middle between the ulnar and radial wrist marker." We identified the trunk using markers on the C7, L3, sternum, and two acromions. We considered the upper part of the human body an articulated system 
composed of rigid bodies corresponding to the following body segments: head, trunk, arm, forearm, and hand. We chose Euler angles to describe the relative movement of the body segments [31]. During the test, we calculated the maximum and minimum angles and the total range of motion (ROM) (in degrees) of the trunk, shoulder, elbow, and wrist. We placed two reflective markers on the pedal and one on the crank axis (Figure 1), which allowed us to measure the crank angle and the angle position of the pedal. "The kinematic data were filtered through a fourth-order digital Butterworth filter with a $6 \mathrm{~Hz}$ cutoff frequency [30].” We used MATLAB (MathWorks, Inc; Natick, Massachusetts) programs to calculate the kinematic data.

\section{Kinetic Data}

We used a freely rotating, instrumented, dynamometric right pedal (Sensy, 9PED version, aluminum; Jumet, Belgium) with an attached handgrip to measure the reaction forces, both radial and tangential [29]. We calibrated this dynamometric pedal by hanging weights from a dynamometric calibration device attached to the pedal while amplifying and recording voltage outputs from foil strain gauges. Weights between 0 and $1,500 \mathrm{~N}$ in the radial direction and from 0 to $500 \mathrm{~N}$ in the tangential direction were used in the calibration. A linear regression equation showed that pedal voltage was a strong predictor of pedal force $\left(R^{2}=0.99\right)$.

We attached two reflective markers to each end of the handgrip-allowing the handgrip center to be calculatedand one on the crank axis to allow the handgrip's angular position $\left(\theta_{2}\right)$ to be obtained and the crank angle $\left(\theta_{1}\right)$ (Figure 4) to be measured with basic trigonometry. In the handgrip reference system, we measured the forces in two dimensions, along the $x$ - and $y$-axes. We used these force components, measured along the handgrip orientation $\left(\theta_{2}\right)$ and the crank angle $\left(\theta_{1}\right)$, to calculate the total, the radial, and the tangential forces, $F_{\text {tot2D }}, F_{r}$, and $F_{\text {tang, }}$, respectively. We calculated the resultant force $\left(F_{\text {tot2D }}\right)$, which is the total force applied to the handgrip, mathematically using the vector sum of the force components, such as

$$
F_{\text {tot } 2 \mathrm{D}}=\sqrt{F_{x}^{2}+F_{y}^{2}}=\sqrt{F_{r}^{2}+F_{\text {tang }}^{2}} \text { (N) . }
$$

We obtained the crank torque $\left(T_{c}\right)$ by multiplying the tangential force $\left(F_{\text {tang }}\right)$ and the crank length $\left(L_{c}\right)$ as

$$
T_{C}=F_{\text {tang }} \times L_{C}(\mathrm{~N} \cdot \mathrm{m}) .
$$

$F_{\text {tang }}$ is the only force component that contributes to the HC's forward motion. The 3-D effectiveness of the force application has been defined as the fraction effective force (FEF) [34]. Since FEF has been previously defined in wheelchair literature as a 3-D measure and because our study only involves two-dimensional (2-D) forces measurements, we will use the notation $\mathrm{FEF}_{2 \mathrm{D}}$ for FEF [29] as

$$
\mathrm{FEF}_{2 \mathrm{D}}=\frac{\int_{0}^{360} F_{\text {tang }}(\theta 1) \cdot d \theta 1}{\int_{0}^{360} F_{\text {tot }}(\theta 1) \cdot d \theta 1} \times 100(\%) .
$$

A cable connected the dynamometric pedal to the Vicon system. The Vicon system synchronously collected the 3-D kinematic data $(60 \mathrm{~Hz})$ and the 2-D kinetic data $(1,200 \mathrm{~Hz})$. We then low-sampled this $1,200 \mathrm{~Hz}$ signal (from 1,200 to $60 \mathrm{~Hz}$ ) using a cubic spline function to synchronize it with the kinematic data. We filtered the kinetic data using a fourth-order digital Butterworth filter with a $10 \mathrm{~Hz}$ cutoff frequency [35] and processed the data of the kinetic measurements with MATLAB.

\section{Statistical Analysis}

For each parameter in each trial, we calculated the mean averages \pm standard deviation (SD) values for the five consecutive complete crank cycles. For kinematic parameters, we calculated the total ROM for the trunk (F/E, rotation, and lateral flexion), the shoulder ( $\mathrm{F} / \mathrm{E}$, internal/external

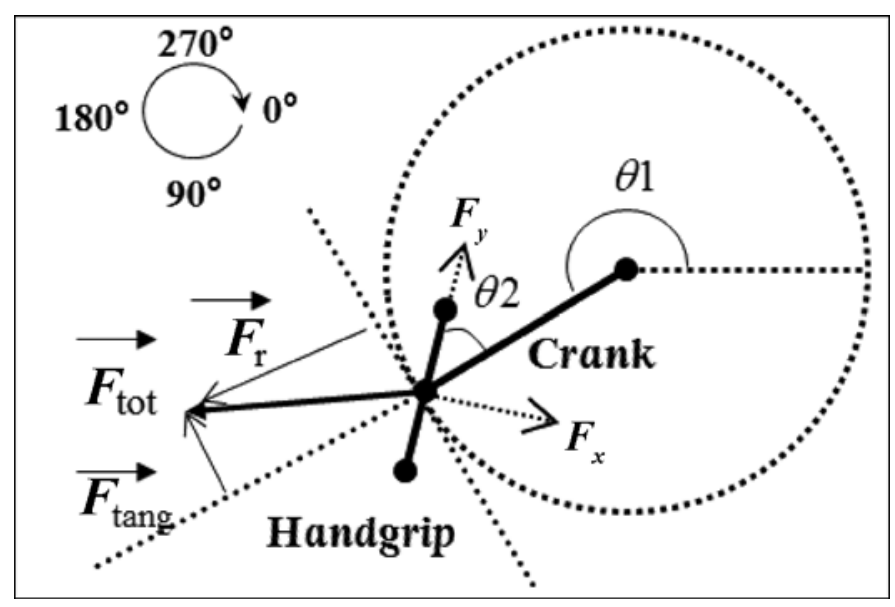

Figure 4.

Schematic representation of force using two-dimensional dynamometric pedal (on right side). Total force $\left(F_{\text {tot }}\right)$, radial force $\left(F_{r}\right)$, and tangential force $\left(F_{\text {tang }}\right)$ were calculated from handgrip orientations $(\theta 2)$ and crank angle $(\theta 1)$ in global reference system. 
rotation, and abduction/adduction), the elbow (F/E) and the wrist (F/E and radial/ulnar deviation). For kinetic parameters, we calculated mean and peak forces of $F_{\text {tot }}, F_{r}, F_{\text {tang, }}$, and $\mathrm{FEF}_{2 \mathrm{D}}$. Furthermore, to investigate kinetics pattern, we divided the $T_{C}$ cycle into four $90^{\circ}$ segments: $0^{\circ}$ to $90^{\circ}, 90^{\circ}$ to $180^{\circ}, 180^{\circ}$ to $270^{\circ}$, and $270^{\circ}$ to $360^{\circ}$. We applied a twofactor analysis of variance for repeated measures with a $2 \times$ 4 design (crank modes: SC and AC, and types of propulsion: AP and ATP [body positions of B45, B85, WB, and $\mathrm{K}]$ ) to determine the effects of crank modes and type of propulsion on the biomechanical parameters. Then, we applied a Bonferroni post hoc test to determine the location of any significant main effects. The level of significance was set at $p<0.05$. We performed all statistical analyses with MATLAB and SPSS statistical software (SPSS, Inc; Chicago, Illinois).

\section{RESULTS}

\section{Kinematic Data}

Table 1 represents the results of kinematic data, expressed as mean \pm SD values for the eight testing conditions. We found significant differences for trunk movement $(p<0.001)$ according to both crank modes and the two types of propulsion, with interaction $(p<0.01)$ between those two factors. The results showed significantly higher elbow $(p<0.001)$ and shoulder $(p<0.01)$ $\mathrm{F} / \mathrm{E}$ in the SC mode versus AC mode. We also found influences of the type of propulsion on internal/external shoulder rotation $(p<0.001)$ and $\mathrm{F} / \mathrm{E}$ elbow $(p<0.001)$.
Concerning the trunk ROM, the locations of any significant main effects obtained by the Bonferroni post hoc test (not represented in Table 1) are represented in Figure 5. The analyses revealed a significant major effect of crank mode on trunk ROM, showing lower lateral flexion and rotation for SC compared with AC. Moreover, the ROM of rotation and lateral flexion of the trunk was higher in the AC mode for ATP propulsion (WB and K). As for the type of propulsion, the statistical analyses showed significant differences in the trunk movement between B45 versus WB, B45 versus $K$, B85 versus $W B$, and B85 versus $K$. Although the F/E of the trunk was higher for both ATP positions (WB and $\mathrm{K}$ ) in the SC (vs AC) mode, this result was not significant for the two other AP propulsion types (B45 and B85).

\section{Kinetic Data}

Table 2 represents the mean averages and SD values of the studied kinetic variables over the five consecutive complete crank cycles. Contrary to results obtained during the kinematic analysis, we found few significant differences between the various test conditions for kinetic parameters. Indeed, the results of Bonferroni post hoc test showed significant differences only for the radial peak force between B45 versus WB, B45 versus K, B85 versus $W B$, and $B 85$ versus $K$ for the $S C$ mode. The results also revealed lower $\mathrm{FEF}_{2 \mathrm{D}}$ mean (in percent) for WB and K compared with B45 and B85 but no significant differences $(p=0.06)$.

Table 1.

Mean \pm standard deviation values of kinematic data obtained from each hand-cycle testing condition.

\begin{tabular}{|c|c|c|c|c|c|c|c|c|c|c|c|}
\hline \multirow{2}{*}{$\begin{array}{c}\text { Range of } \\
\left.\text { Motion ( }{ }^{\circ}\right)\end{array}$} & \multicolumn{2}{|c|}{ B45 } & \multicolumn{2}{|c|}{ B85 } & \multicolumn{2}{|c|}{ WB } & \multicolumn{2}{|c|}{$\mathbf{K}$} & \multicolumn{3}{|c|}{$\begin{array}{c}\text { ANOVA } \\
\text { (p-Value) }\end{array}$} \\
\hline & SC & AC & SC & AC & SC & AC & SC & AC & Type & Mode & Inter \\
\hline \multicolumn{12}{|l|}{ Trunk } \\
\hline $\mathrm{F} / \mathrm{E}$ & $2.1 \pm 1.7$ & $1.4 \pm 0.7$ & $1.3 \pm 0.9$ & $1.1 \pm 0.7$ & $11.9 \pm 4.4$ & $2.6 \pm 1.4$ & $12.8 \pm 5.3$ & $1.7 \pm 0.8$ & 0.001 & 0.001 & 0.01 \\
\hline $\mathrm{LFr} / \mathrm{LFl}$ & $0.8 \pm 0.5$ & $5.0 \pm 2.9$ & $0.7 \pm 0.4$ & $3.9 \pm 2.8$ & $1.0 \pm 0.4$ & $7.5 \pm 2.3$ & $1.3 \pm 0.5$ & $6.1 \pm 1.9$ & 0.001 & 0.001 & 0.01 \\
\hline $\mathrm{Rr} / \mathrm{Rl}$ & $1.8 \pm 0.4$ & $15.1 \pm 8.1$ & $1.9 \pm 1.0$ & $13.1 \pm 6.9$ & $3.2 \pm 2.3$ & $31.4 \pm 10.6$ & $3.4 \pm 2.0$ & $26.8 \pm 7.6$ & 0.001 & 0.001 & 0.01 \\
\hline \multicolumn{12}{|l|}{ Shoulder } \\
\hline $\mathrm{F} / \mathrm{E}$ & $62.0 \pm 4.7$ & $52.8 \pm 7.2$ & $65.6 \pm 4.3$ & $59.2 \pm 6.7$ & $56.1 \pm 2.3$ & $46.5 \pm 6.1$ & $58.5 \pm 1.4$ & $51.9 \pm 6.0$ & 0.001 & 0.01 & NS \\
\hline $\mathrm{Ad} / \mathrm{Ab}$ & $14.6 \pm 5.5$ & $13.2 \pm 5.5$ & $13.9 \pm 7.2$ & $12.6 \pm 6.2$ & $13.0 \pm 4.8$ & $17.3 \pm 4.8$ & $11.0 \pm 1.6$ & $17.6 \pm 3.4$ & NS & NS & NS \\
\hline $\mathrm{Ri} / \mathrm{Re}$ & $11.4 \pm 5.6$ & $9.7 \pm 4.2$ & $10.2 \pm 4.6$ & $8.5 \pm 4.0$ & $11.1 \pm 3.6$ & $13.5 \pm 8.1$ & $12.8 \pm 6.2$ & $16.7 \pm 6.6$ & 0.01 & NS & 0.05 \\
\hline Elbow F/E & $76.3 \pm 7.5$ & $69.2 \pm 8.4$ & $73.9 \pm 11.9$ & $68.4 \pm 6.3$ & $63.4 \pm 13.9$ & $57.6 \pm 9.4$ & $60.5 \pm 6.7$ & $60.7 \pm 10.3$ & 0.001 & 0.001 & NS \\
\hline \multicolumn{12}{|l|}{ Wrist } \\
\hline $\mathrm{F} / \mathrm{E}$ & $18.2 \pm 10.3$ & $16.8 \pm 9.7$ & $15.7 \pm 11.0$ & $15.7 \pm 9.3$ & $15.4 \pm 8.4$ & $19.3 \pm 8.3$ & $13.7 \pm 5.9$ & $14.5 \pm 7.9$ & NS & NS & NS \\
\hline $\mathrm{Ir} / \mathrm{Iu}$ & $15.1 \pm 6.1$ & $15.4 \pm 6.1$ & $17.9 \pm 6.9$ & $19.2 \pm 13.1$ & $15.0 \pm 4.0$ & $13.1 \pm 6.1$ & $14.8 \pm 4.1$ & $14.7 \pm 5.2$ & NS & NS & NS \\
\hline
\end{tabular}




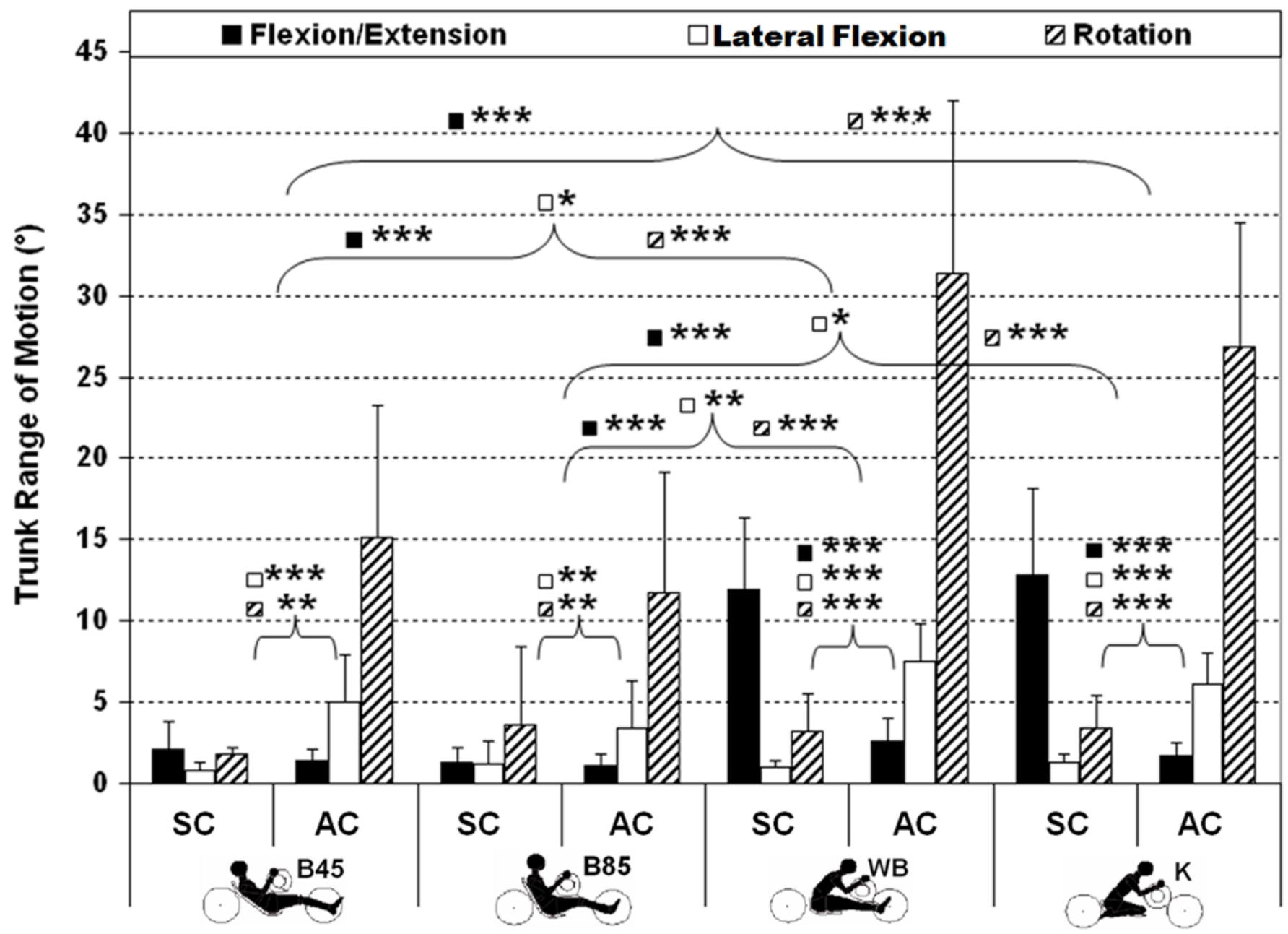

Hand-Cycling Testing Conditions

Figure 5.

Trunk range of motion (in degrees) according to eight hand-cycle testing conditions. Significant differences: ${ }^{*} p<0.05,{ }^{* *} p<0.01,{ }^{* * *} p<0.001$. AC $=$ asynchronous, $\mathrm{B} 45=$ backrest angle of $45^{\circ}$, B85 = backrest angle of $85^{\circ}, \mathrm{K}=$ kneeling position, $\mathrm{SC}=$ synchronous, $\mathrm{WB}=$ without backrest.

With respect to $T_{C}$ (Figure 6), the statistical analysis revealed a significant main effect of crank mode with lower $T_{C}$ in SC versus AC for phase $1\left(0^{\circ}-90^{\circ}\right)$ and inversely a higher $T_{C}$ in SC versus AC for phase $3\left(180^{\circ}-\right.$ $270^{\circ}$ ). As for the type of propulsion, only SC between $\mathrm{B} 45$ and $\mathrm{K}$ for phases 3 and $4\left(270^{\circ}-360^{\circ}\right)$ showed significant differences.

\section{DISCUSSION}

\section{Effects of Mode of Propulsion and Hand-Cycle Configuration in Trunk Range of Motion}

The statistical analyses (Table $\mathbf{1}$ and Figure 5) revealed a significant major effect of crank mode on the
ROM of the trunk. The result showed a higher F/E of the trunk for the ATP type of propulsion (WB and K) in the SC versus $\mathrm{AC}$ mode. Indeed, trunk $\mathrm{F} / \mathrm{E}$ was the highest for WB $\left(11.9^{\circ} \pm 4.4^{\circ}\right)$ and $\mathrm{K}\left(12.8^{\circ} \pm 5.3^{\circ}\right)$ in the SC mode than for WB $\left(2.6^{\circ} \pm 1.4^{\circ}\right)$ and $\mathrm{K}\left(1.7^{\circ} \pm 0.8^{\circ}\right)$ in the AC mode. Inversely, the lateral flexion and rotation are lower in SC versus AC whatever the type of propulsion. The biggest difference of the ROM between $\mathrm{SC}$ versus $\mathrm{AC}$ is for trunk rotation amplitude in $\mathrm{WB}\left(3.2^{\circ} \pm 2.3^{\circ}\right.$ vs $31.4^{\circ} \pm$ $10.6^{\circ}$ ).

To our knowledge, no previous study has determined the effect of crank mode on the ROM of the trunk. However in the literature, two studies emit the hypothesis that the beneficial effects of the SC arm mode may also be 
Table 2.

Mean \pm standard deviation values of different kinetic parameters measured during eight hand-cycle testing conditions.

\begin{tabular}{|c|c|c|c|c|c|c|c|c|c|c|c|}
\hline Parameter & \multicolumn{2}{|c|}{ B45 } & \multicolumn{2}{|c|}{ B85 } & \multicolumn{2}{|c|}{ WB } & \multicolumn{2}{|c|}{$\mathbf{K}$} & \multicolumn{3}{|c|}{$\begin{array}{c}\text { ANOVA } \\
(p \text {-Value) }\end{array}$} \\
\hline$\overline{T_{C}(\mathrm{~N} \cdot \mathrm{m})}$ & $9.4 \pm 0.8$ & $10.0 \pm 3.4$ & $8.7 \pm 2.0$ & $9.9 \pm 2.5$ & $9.1 \pm 1.6$ & $9.4 \pm 1.7$ & $8.0 \pm 1.7$ & $8.8 \pm 2.2$ & NS & NS & NS \\
\hline \multicolumn{12}{|l|}{ Peak Forces } \\
\hline Radial & $31.7 \pm 12.3$ & $47.3 \pm 15.0$ & $42.6 \pm 17.2$ & $50.1 \pm 24.7$ & $76.8 \pm 31.1$ & $58.8 \pm 23.4$ & $70.5 \pm 17.3$ & $46.5 \pm 19.2$ & 0.05 & NS & 0.05 \\
\hline
\end{tabular}

$\mathrm{AC}=$ asynchronous, $\mathrm{ANOVA}=$ analysis of variance, $\mathrm{B} 45=$ backrest angle of $45^{\circ}, \mathrm{B} 85=$ backrest angle of $85^{\circ}, \mathrm{FEF}_{2 \mathrm{D}}=$ two-dimensional fraction effective force, Inter $=$ interaction between propulsion type and crank mode, $\mathrm{K}=$ kneeling position, $\mathrm{NS}=$ nonsignificant, $\mathrm{SC}=$ synchronous, $T_{C}=$ crank torque, $\mathrm{WB}=$ without backrest.

caused by the larger effective muscle mass of the trunk, which allows the weight of the trunk to be effectively used in propulsion [20-21]. With proper trunk control, trunk flexors and extensors will actively produce power. On the contrary, the alternating character of the movement in AC requires more trunk stabilization.

Our results do not fully agree with this hypothesis. Although the $\mathrm{F} / \mathrm{E}$ of the trunk is greater for both ATP positions (WB and $\mathrm{K}$ ) in the SC (vs AC) mode, we did not find this result for the two other AP propulsion types (B45 and B85). Consequently, F/E of the trunk does not have a main role in these conditions. Moreover, AC causes a higher rotation and lateral flexion of the trunk in the ATP versus AP propulsion. Thus, we conclude that, in AC mode, the trunk muscles not only stabilize but also propel the nondisabled participant.

Concerning HC configuration, the kinematic characteristic (Table 1) substantially showed significant differences, especially for the trunk ROM according to the four types of body positions (B45, B85, WB, and K). The results indicated no significant difference in the trunk ROM between B45 versus B85 and between WB versus $\mathrm{K}$. Thus, the ROM of the trunk was higher in ATP propulsion (WB and $\mathrm{K}$ ) than in AP propulsion (B45 and B85). Our results are consistent with the first results of Faupin et al. [24]. Although their study design differed from the present study with respect to the test condition (8 s maximal sprints), they also reported both a statistically higher trunk F/E and maximal-reached velocity without use of a backrest compared with two backrest adjustments (angle slope ranging to $45^{\circ}$ and $65^{\circ}$ ).

Indeed, we can hypothesize that the ATP types of propulsion (WB and $\mathrm{K}$ ) would allow the athlete to use the trunk muscles actively during the propulsive phase. Contrary to ATP, the use of the trunk muscles during AP propulsion
(B45 and B85) was difficult because of the semilengthened position. The AP propulsion is realized because of the arms. As a result, a better stability of the user in the HC was achieved in AP propulsion. Disabled persons with limited trunk function, such as spinal cord injuries, mainly use this type of propulsion, whereas persons with less-severe disabilities, such as athletes with lower-limb amputees, more often use ATP HC. For verifying the current findings, future studies should focus on disabled HC users.

\section{Kinetic and Kinematic Responses of Upper-Limb to SC Versus AC Propulsion Mode and AP Versus ATP Propulsion Type}

In a general way, whatever type and mode of propulsion, torque values $(\mathrm{N} \cdot \mathrm{m})$ are not significantly different (Table 2). However, concerning the torque pattern for the four $90^{\circ}$ segments, Figure 6 shows a significant effect of crank mode with lower torque in SC compared with AC for phase $1\left(0^{\circ}-90^{\circ}\right)$ and inversely a higher torque in SC versus $A C$ for phase $3\left(180^{\circ}-270^{\circ}\right)$ whatever the type of propulsion. Moreover, significant differences appeared in SC between B45 and K for phases 3 and 4. This result may be related to the different uses of the trunk and joint ROM of the shoulder and elbow. Indeed, the statistical results revealed a higher elbow and shoulder F/E in ATP (WB and K) versus AP (B45 and B85) and a significantly higher elbow and shoulder F/E in the SC mode versus AC mode. Such angle variations may be caused by the trunk ROM, and the fact that in $\mathrm{K}$, the shoulders were above the cranks, whereas for B45, they were below the cranks.

In the current study, the calculated $\mathrm{FEF}_{2 \mathrm{D}}$ value is between 72.9 and 89.3 percent. Our results are consistent with the first results of Hettinga et al., who found mean FEF between 79 and 83 percent [25]. However, results in 

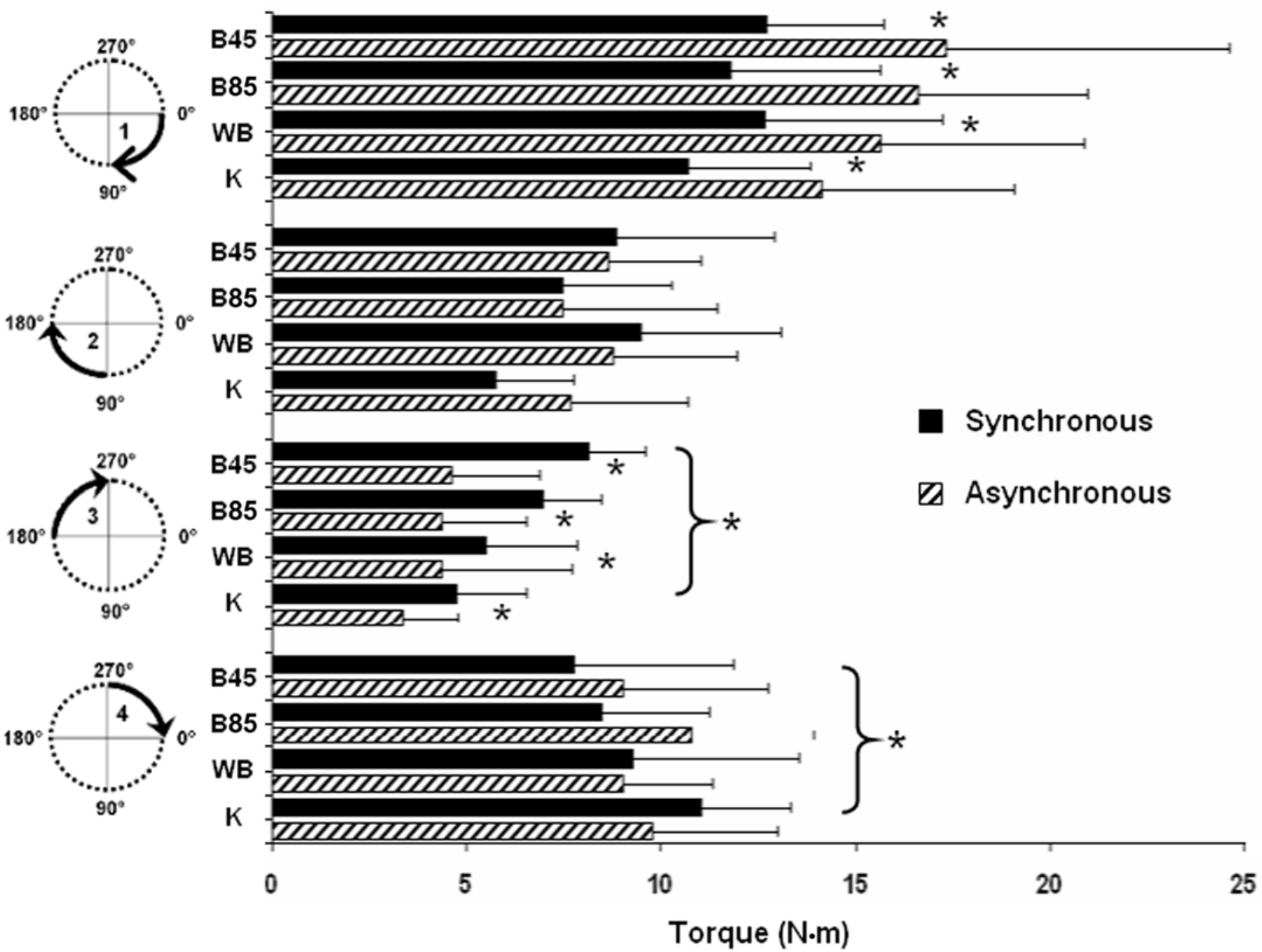

Figure 6.

Torque $(\mathrm{N} \cdot \mathrm{m})$ for four $90^{\circ}$ segments according to eight hand-cycle testing conditions. * Significant difference $(p<0.05)$ between synchronous and asynchronous crank mode or between $\mathrm{K}$ and B45. B45 = backrest angle of $45^{\circ}$, B85 = backrest angle of $85^{\circ}, \mathrm{K}=\mathrm{kneeling}$ position, $\mathrm{WB}=$ without backrest.

Table 2 do not indicate which mode and type of propulsion were the most effective (FEF). We found no significant difference between AC versus SC and ATP (WB and K) versus AP (B45 and B85) for the FEF parameter (Table 2). Moreover, these counterintuitive findings showed results with relative lower $\mathrm{FEF}_{2 \mathrm{D}}$ mean (percent) in $\mathrm{WB}$ and $\mathrm{K}$ than in B45 and B85 (but no significant difference, $p=$ 0.06). Indeed, the results of the Bonferroni post hoc test revealed, for the SC mode, a higher radial peak force in ATP (WB and K) versus AP (B45 and B85). To explain this latter finding, we can assume that the use of the trunk during ATP propulsion might lower stability, and conse- quently, the application of force would be less effective. Indeed, instability would cause the participant to apply less tangential force and increase radial force.

\section{Limitations and Future Recommendations}

All participants in our study had no previous experience in hand cycling. Studying the effects of ergonomic adjustments and design within an inexperienced population has already demonstrated their value in hand cycling [20-24,36-37]. Consequently, this study was completed within a homogenous and equally trained subject group. Moreover, the participants could not be accustomed in any 
way to a specific trunk ROM, especially to a particular type or mode of propulsion. A shortcoming might be that we collected our data from nondisabled participants: these results are thus not completely transferable to novice wheelchair-dependent users. Although our results help us better understand trunk use during the hand-cycling propulsion phase, future studies with different populations, especially persons with limited trunk function, still need to be done.

In the current study, we placed the HC on a stationary ergometer (Elite Axiom). The use of a stationary ergometer could explain why the participants had no problem keeping the front wheel parallel to the propelling direction during the AC mode in hand cycling. One should be cautious extrapolating these data since a steering condition was not permitted. Indeed, steering is suggested to involve trunk function in a different way. Moreover, the ergometer does not measure precisely the rolling resistance on the two back wheels, thus precisely calculating power output was not possible. In addition, the Elite Axiom tends to overestimate the average power [27]. However, the calculated values for rolling resistance on the front wheel are reliable and thus can be used for intersubject comparisons. Both mechanical efficiency (from power output and oxygen uptake) and biomechanical parameter must be studied in the field condition for further ergonomic optimization of HC.

\section{CONCLUSIONS}

In this study performed with seven novice nondisabled subjects, the main findings are the differences in the use of the trunk movement according to both crank modes (SC and AC) and two types of propulsion (AP and ATP). Higher F/E of the trunk was observed during ATP versus AP propulsion, and higher lateral flexion and rotation of the trunk in AC versus SC mode. These results demonstrated more trunk movement during ATP type and AC mode of hand cycling. Trunk ROM should explain the different force generation patterns observed in this investigation between AC and SC modes and AP and ATP types. However, kinetic results did not establish the most effective type or mode of propulsion. In conclusion, trunk movement is an important parameter to consider for ergonomic optimization of hand cycling. The results of this study should be confirmed in experienced HC users, especially with limited trunk function, and in conditions that are more realistic.

\section{ACKNOWLEDGMENTS}

\section{Author Contributions:}

Study concept and design: A. Faupin, P. Gorce.

Acquisition of data: A. Faupin.

Analysis and interpretation of data: A. Faupin, P. Gorce, C. Meyer.

Drafting of manuscript: A. Faupin, P. Gorce, C. Meyer.

Critical revision of manuscript for important intellectual content:

A. Faupin, P. Gorce, C. Meyer.

Statistical analysis: A. Faupin.

Obtained funding: A. Faupin, P. Gorce.

Administrative, technical, or material support: A. Faupin, P. Gorce.

Study supervision: A. Faupin, P. Gorce.

Financial Disclosures: The authors have declared that no competing interests exist.

Funding/Support: This material is the result of work supported with resources and the use of facilities at the Institut Garches (Hôpital Raymond Poincaré, 104, boulevard Raymond-Poincaré, 92380 Garches). Additional Contributions: The authors would like to thank Pr. Olivier Remy-Neris and Pr. Andre Thevenon for their scientific help and Stéphane Bouilland for her technical assistance during the experiment. This project was performed in the J. Calvé center (Groupe Hopale, 72 esplanade Parmentier, 62608 Berck sur mer). The authors would also like to thank the Institut Garches, which allowed them to perform this project.

Institutional Review: The study was designed in accordance with the ethical standards of the Helsinki Declaration of 1975 and received the approval of the local Consultative Committee for the Protection of Persons in Biomedical Research. All procedures were fully explained to the participants who gave their written informed consent to participate. Participant Follow-Up: The authors do not plan to inform the participants of the publication of this study because of a lack of contact information.

\section{REFERENCES}

1. Martel G, Noreau L, Jobin J. Physiological responses to maximal exercise on arm cranking and wheelchair ergometer with paraplegics. Paraplegia. 1991;29(7):447-56.

[PMID: 1784511]

DOI:10.1038/sc.1991.61

2. Sawka MN, Glaser RM, Wilde SW, Von Luhrte TC. Metabolic and circulatory responses to wheelchair and arm crank exercise. J Appl Physiol. 1980;49(5):784-88.

[PMID: 6776077]

3. Smith PA, Glaser RM, Petrofsky JS, Underwood PD, Smith GB, Richard JJ. Arm crank vs handrim wheelchair propulsion: Metabolic and cardiopulmonary responses. Arch Phys Med Rehabil. 1983;64(6):249-54. [PMID: 6860094] 
4. Wicks JR, Oldridge NB, Cameron BJ, Jones NL. Arm cranking and wheelchair ergometry in elite spinal cordinjured athletes. Med Sci Sports Exerc. 1983;15(3):224-31. [PMID: 6621310] DOI:10.1249/00005768-198315030-00008

5. Dallmeijer AJ, Zentgraaff ID, Zijp NI, Van der Woude LH. Submaximal physical strain and peak performance in handcycling versus handrim wheelchair propulsion. Spinal Cord. 2004;42(2):91-98. [PMID: 14765141] DOI:10.1038/sj.sc.3101566

6. Mukherjee G, Samanta A. Physiological response to the ambulatory performance of hand-rim and arm-crank propulsion systems. J Rehabil Res Dev. 2001;38(4):391-99. [PMID: 11563492]

7. Abel T, Kröner M, Rojas Vega S, Peters C, Klose C, Platen P. Energy expenditure in wheelchair racing and handbiking-A basis for prevention of cardiovascular diseases in those with disabilities. Eur J Cardiovasc Prev Rehabil. 2003; 10(5):371-76. [PMID: 14663299] DOI:10.1097/01.hjr.0000096542.30533.59

8. Janssen TW, Dallmeijer AJ, Van der Woude LH. Physical capacity and race performance of handcycle users. J Rehabil Res Dev. 2001;38(1):33-40. [PMID: 11322469]

9. Langbein WE, Maki KC. Predicting oxygen uptake during counterclockwise arm crank ergometry in men with lower limb disabilities. Arch Phys Med Rehabil. 1995;76(7):642-46. [PMID: 7605183]

DOI:10.1016/S0003-9993(95)80633-4

10. Mukherjee G, Bhowmik P, Samanta A. Effect of chronic use of different propulsion systems in wheelchair design on the aerobic capacity of Indian users. Indian J Med Res. 2005;121(6):747-58. [PMID: 16037619]

11. Verellen J, Theisen D, Vanlandewijck Y. Influence of crank rate in hand cycling. Med Sci Sports Exerc. 2004;36(10): 1826-31. [PMID: 15595307]

DOI:10.1249/01.MSS.0000142367.04918.5A

12. Van der Woude LH, Dallmeijer AJ, Janssen TW, Veeger D. Alternative modes of manual wheelchair ambulation: An overview. Am J Phys Med Rehabil. 2001;80(10):765-77.

[PMID: 11562560]

DOI:10.1097/00002060-200110000-00012

13. Van der Woude LH, Veeger HE, Dallmeijer AJ, Janssen TW, Rozendaal LA. Biomechanics and physiology in active manual wheelchair propulsion. Med Eng Phys. 2001;23(10): 713-33. [PMID: 11801413] DOI:10.1016/S1350-4533(01)00083-2

14. Hopman MT, Van Teeffelen WM, Brouwer J, Houtman S, Binkhorst RA. Physiological responses to asynchronous and synchronous arm-cranking exercise. Eur J Appl Physiol Occup Physiol. 1995;72(1-2):111-14. [PMID: 8789580] DOI:10.1007/BF00964124

15. Marincek CR, Valencic V. Arm cycloergometry and kinetics of oxygen consumption in paraplegics. Paraplegia. 1977;
15(2):178-85. [PMID: 909722]

DOI:10.1038/sc.1977.25

16. Mossberg K, Willman C, Topor MA, Crook H, Patak S. Comparison of asynchronous versus synchronous arm crank ergometry. Spinal Cord. 1999;37(8):569-74. [PMID: 10455533] DOI:10.1038/sj.sc.3100875

17. Goosey-Tolfrey VL, Sindall P. The effects of arm crank strategy on physiological responses and mechanical efficiency during submaximal exercise. J Sports Sci. 2007; 25(4):453-60. [PMID: 17365532]

DOI:10.1080/02640410600702883

18. Abel T, Rojas Vega S, Bleicher I, Platen P. Hand biking: Physiological responses to synchronous and asynchronous crank montage. Eur J Sport Sci. 2003;3:1-8.

19. Dallmeijer AJ, Van der Woude LH, Ottjes L, De Waardt E. Comparison of synchronous and asynchronous hand cycling at different cadences. Med Sci Sports Exerc. 2001;33(5):S321. DOI:10.1097/00005768-200105001-01799

20. Dallmeijer AJ, Ottjes L, De Waardt E, Van der Woude LH. A physiological comparison of synchronous and asynchronous hand cycling. Int J Sports Med. 2004;25(8):622-26. [PMID: 15532007] DOI:10.1055/s-2004-817879

21. Van der Woude LH, Bosmans I, Bervoets B, Veeger HE. Handcycling: Different modes and gear ratios. J Med Eng Technol. 2000;24(6):242-49. [PMID: 11315650] DOI:10.1080/030919000300037168

22. Van der Woude LH, Horstman A, Faas P, Mechielsen S, Bafghi HA, De Koning JJ. Power output and metabolic cost of synchronous and asynchronous submaximal and peak level hand cycling on a motor driven treadmill in able-bodied male subjects. Med Eng Phys. 2008;30(5): 574-80. [PMID: 17709272] DOI:10.1016/j.medengphy.2007.06.006

23. Bafghi HA, De Haan A, Horstman A, Van der Woude L. Biophysical aspects of submaximal hand cycling. Int J Sports Med. 2008;29(8):630-38. [PMID: 18213544$]$ DOI:10.1055/s-2007-989416

24. Faupin A, Gorce P, Meyer C, Thevenon A. Effects of backrest positioning and gear ratio on nondisabled subjects' handcycling sprinting performance and kinematics. J Rehabil Res Dev. 2008;45(1):109-16. [PMID: 18566929] DOI:10.1682/JRRD.2006.10.0139

25. Hettinga FJ, Valent L, Groen W, Van Drongelen S, De Groot S, Van der Woude LH. Hand-cycling: An active form of wheeled mobility, recreation, and sports. Phys Med Rehabil Clin N Am. 2010;21(1):127-40. [PMID: 19951782] DOI:10.1016/j.pmr.2009.07.010

26. Goosey-Tolfrey VL, Alfano H, Fowler N. The influence of crank length and cadence on mechanical efficiency in hand cycling. Eur J Appl Physiol. 2008;102(2):189-94.

[PMID: 17909841] DOI:10.1007/s00421-007-0576-7 
27. Van Breukelen K. Handbikes: Arm power versus arm trunk power, an ergonomic classification of handbikes [Internet]. Gouda: the Netherlands; Arm Powered by Double Performance; 2001 Available from: http://www.handbike.de/ archiv/2002/downloads/arm-vs-trunk.pdf

28. Bertucci W, Duc S, Villerius V, Grappe F. Validity and reliability of the Axiom PowerTrain cycle ergometer when compared with an SRM powermeter. Int J Sports Med. 2005; 26(1):59-65. [PMID: 15643536] DOI:10.1055/s-2004-817855

29. Faupin A, Gorce P, Watelain E, Meyer C, Thevenon A. A biomechanical analysis of handcycling: A case study. J Appl Biomech. 2010;26(2):240-45. [PMID: 20498497]

30. Faupin A, Gorce P, Campillo P, Thevenon A, Rémy-Néris O. Kinematic analysis of handbike propulsion in various gear ratios: Implications for joint pain. Clin Biomech (Bristol, Avon). 2006;21(6):560-66. [PMID: 16510220]

DOI:10.1016/j.clinbiomech.2006.01.001

31. Roux E, Bouilland S, Godillon-Maquinghen AP, Bouttens D. Evaluation of the global optimisation method within the upper limb kinematics analysis. J Biomech. 2002;35(9): 1279-83. [PMID: 12163317] DOI:10.1016/S0021-9290(02)00088-X

32. Wu G, Cavanagh PR. ISB recommendations for standardization in the reporting of kinematic data. J Biomech. 1995; 28(10):1257-61. [PMID: 8550644]

DOI:10.1016/0021-9290(95)00017-C

33. Schmidt R, Disselhorst-Klug C, Silny J, Rau G. A markerbased measurement procedure for unconstrained wrist and elbow motions. J Biomech. 1999;32(6):615-21.

[PMID: 10332626]

DOI:10.1016/S0021-9290(99)00036-6
34. Veeger HE, Van der Woude LH, Rozendal RH. Load on the upper extremity in manual wheelchair propulsion. J Electromyogr Kinesiol. 1991;1(4):270-80. [PMID: 20870518] DOI:10.1016/1050-6411(91)90014-V

35. Cooper RA, DiGiovine CP, Boninger ML, Shimada SD, Robertson RN. Frequency analysis of 3-dimensional pushrim forces and moments for manual wheelchair propulsion. Automedica. 1998;16:355-65.

36. Krämer C, Hilker L, Böhm H. Influence of crank length and crank width on maximal hand cycling power and cadence. Eur J Appl Physiol. 2009;106(5):749-57.

[PMID: 19434421] DOI:10.1007/s00421-009-1062-1

37. Krämer C, Schneider G, Böhm H, Klöpfer-Krämer I, Senner V. Effect of different handgrip angles on work distribution during hand cycling at submaximal power levels. Ergonomics. 2009;52(10):1276-86. [PMID: 19626501]

Submitted for publication October 14, 2010. Accepted in revised form March 30, 2011.

This article and any supplementary material should be cited as follows:

Faupin A, Gorce P, Meyer C. Effects of type and mode of propulsion on hand-cycling biomechanics in nondisabled subjects. J Rehabil Res Dev. 2011;48(9):1049-60. DOI:10.1682/JRRD.2010.10.0199

ResearcherID: Arnaud Faupin, PhD: F-2925-2011

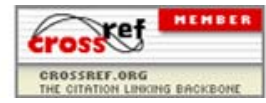


